\title{
Comparative genomic analysis of the flagellin glycosylation island of the Gram-positive thermophile Geobacillus
}

\author{
Pieter De Maayer ${ }^{1 *}$ and Don A. Cowan ${ }^{2}$
}

\begin{abstract}
Background: Protein glycosylation involves the post-translational attachment of sugar chains to target proteins and has been observed in all three domains of life. Post-translational glycosylation of flagellin, the main structural protein of the flagellum, is a common characteristic among many Gram-negative bacteria and Archaea. Several distinct functions have been ascribed to flagellin glycosylation, including stabilisation and maintenance of the flagellar filament, motility, surface recognition, adhesion, and virulence. However, little is known about this trait among Gram-positive bacteria.

Results: Using comparative genomic approaches the flagellin glycosylation loci of multiple strains of the Gram-positive thermophilic genus Geobacillus were identified and characterized. Eighteen of thirty-six compared strains of the genus carry these loci, which show evidence of horizontal acquisition. The Geobacillus flagellin glycosylation islands (FGls) can be clustered into five distinct types, which are predicted to encode highly variable glycans decorated with distinct and heavily modified sugars.

Conclusions: Our comparative genomic analyses showed that, while not universal, flagellin glycosylation islands are relatively common among members of the genus Geobacillus and that the encoded flagellin glycans are highly variable. This suggests that flagellin glycosylation plays an important role in the lifestyles of members of this thermophilic genus.
\end{abstract}

Keywords: Geobacillus, Flagellin, Post-translational modification, Glycosylation, Glycosyltransferase, Pseudaminic acid

\section{Background}

While long considered to be specific to eukaryotes, protein glycosylation is now known to be common in both Bacteria and Archaea, with even greater versatility in both glycan structure and composition observed in prokaryotic cells than in their eukaryotic counterparts [1]. This protein modification has a substantive effect on both the structure and function of the protein [2]. A large number of target proteins for posttranslational glycan modification have been identified, and include surface proteins such as pili, lipoproteins, adhesins and the surface layer proteins in many Archaea and Gram-positive bacteria, as well as secreted proteins such as antigens and

\footnotetext{
* Correspondence: Pieter.demaayer@wits.ac.za

'School of Molecular and Cell Biology, University of the Witwatersrand,

Private Bag 3, Wits, 2050, Johannesburg, South Africa

Full list of author information is available at the end of the article
}

pathogenicity effectors $[1,2]$. Two discrete mechanisms for glycan transfer to the target protein have been identified, where the glycan chains are either assembled on a lipid carrier and transferred to the protein by oligosaccharyltransferases, or the sugars are sequentially attached by glycosyltransferases to the target protein [3]. Furthermore, glycans can be linked to distinct amino acids in prokaryotic proteins via $N$-linkage to the amide group of asparagines, or $O$-linked to the hydroxyl group of serine or threonine residues $[3,4]$.

The most extensively characterized post-translationally glycosylated protein is flagellin, the main structural unit of the flagellum, the whip-like appendage required for swimming motility. The $\mathrm{C}$ - and N-termini of flagellin proteins are very conserved, while the central region is highly variable and forms the surface-exposed portion of the protein [5]. Flagellin glycan linkages are generally 
restricted to this region and glycans are thus exposed to the environment $[4,6]$. Flagellin glycosylation occurs in both Archaea and Bacteria, where in the former it occurs mainly in the $N$-linked conformation, while in the later the flagellin is generally $O$-glycosylated [7]. Diverse functions have been ascribed to flagellin glycosylation. In the Gram-negative bacterial pathogens Campylobacter and Aeromonas, the aquatic bacterium Caulobacter crescentus and the Gram-positive bacterium Paenibacillus alvei, flagellin glycosylation is imperative for assembly of the flagellum and flagellar motility [7-10]. By contrast, glycosylation gene deletion in the opportunistic human pathogen Pseudomonas aeruginosa and plant pathogen Pseudomonas syringae had no direct effect on assembly or motility $[11,12]$. As flagellin is a highly immunogenic protein recognised by the host during infection, flagellin glycosylation in Gram-negative pathogens can facilitate immune evasion [13, 14]. Other purported functions of flagellin glycosylation include surface recognition, attachment and adhesion, biofilm formation, increased resistance against proteolytic degradation and virulence [15-17]. Similarly, in Archaea, glycosylation has also been shown to be essential for flagellar biosynthesis and motility in some species, while $\mathrm{N}$-glycosylation of flagella has been suggested to contribute to their ability to survive under harsh environmental conditions [18].

While flagellin glycosylation is a well-documented feature in Gram-negative bacteria and Archaea, it has only been observed in a limited number of Grampositive taxa, including members of the genera Listeria, Clostridium, Butyrivibrio and Paenibacillus [7, 8, 12]. Moreover, the molecular determinants of flagellin glycosylation have only been studied in one Gram-positive bacterium, Clostridium botulinum [19]. Members of the genus Geobacillus are Gram-positive, rod-shaped, aerobic, obligate thermophiles. This genus currently comprises 16 species which are commonly isolated from high temperature environments, including hot springs, oil wells and compost although they have also been isolated from more temperate environments. Geobacillus spp. have received extensive interest as the sources of a range of thermostable enzymes with various industrial and biotechnological applications [20-22]. Periodic acid Schiff (PAS) staining demonstrated that the flagellin of Geobacillus stearothermophilus $\mathrm{NBRC} 12550^{\mathrm{T}}$ is glycosylated [23]. Here, using comparative genomic analyses, we show the presence of flagellin glycosylation islands (FGIs) in the genome sequences of half of the 36 compared Geobacillus strains. These FGIs are highly variable, suggesting that these Geobacillus strains have the genetic potential to synthesise distinct, extensively decorated flagellin glycans. Finally, we discuss potential functional roles for flagellin glycosylation in Geobacillus spp.

\section{Results and discussion}

\section{General properties of the Geobacillus FGIs}

The complete and draft genomes of 36 Geobacillus strains were analyzed for the presence of genomic islands using the IslandViewer server [24]. A predicted genomic island was found to be integrated within a flagellar biosynthetic locus conserved in all sequenced Geobacillus strains. This locus is comprised of genes coding for the main flagellar filament subunit (flaA1 and flaA2), filament cap protein $(f l i D)$ flagellar hook-filament proteins $(f l g K$ and $f l g L)$, the flagellar export proteins (fliS, $f l i T, f l h B, f(g N)$ and the anti-sigma factor $(f l g M)$ [25]. The genomic island is localized between the flagellin gene flaA2 and flaG, which codes for a flagellar protein of unknown function. The island varies in size from 0.9 to $30.4 \mathrm{~kb}$. The protein coding sequences (CDSs) for these regions were predicted, and in fifteen of the sequenced Geobacillus strains, CDSs coding for glycosyltransferases were present. Three additional strains did not encode glycosyltransferases in this locus, but did code for predicted motility-associated factors (Maf proteins). Orthologs of maf genes have been identified in Aeromonas spp., Helicobacter spp. and Campylobacter spp., with seven maf genes (maf1-maf7) occurring in the flagellin glycosylation locus of Campylobacter jejuni NCTC 11168 [26, 27]. The exact function of these Maf proteins remains unclear, although the genetic localisation of the maf genes, as well as the unglycosylated flagellin phenotypes of maf knock-out mutants, suggests a role in glycosylation [26, 27]. Molecular evidence for Aeromonas caviae suggests that the Maf proteins represent a novel family of flagellin glycosyltransferases [9]. The three Geobacillus strains lacking a glycosyltransferase gene, but with a maf gene in their flagellin loci, were thus considered to be $\mathrm{FGI}^{+}$(Fig. 1). As such, 18 out of the 36 Geobacillus strains were considered to carry a flagellin glycosylation island $\left(\mathrm{FGI}^{+}\right)$, while the remaining 18 strains were considered to be FGI negative $\left(\mathrm{FGI}^{-}\right)$(Fig. 2).

A Maximum Likelihood phylogeny of the 36 Geobacillus strains, and type strains of each of validly described species, was constructed on the basis of the recN gene. This gene has been shown to result in similar branching patterns as 16S rRNA phylgeny, albeit with greater resolving power between closely related strains, and closely reflects the whole genome relatedness of Geobacillus species, as well as a range of other Gram-positive and Gram-negative taxa [28, 29]. This phylogeny (Fig. 3) shows the absence of a flagellin glycosylation island in some species for which more than one genome sequence is available, including G. stearothermophilus and G. caldoxylosilyticus, while FGIs are present in all four sequenced G. thermoglucosidans strains. By contrast, the G. kaustophilus-thermoleovorans-vulcaniilituanicus clade showed a more random distribution in 


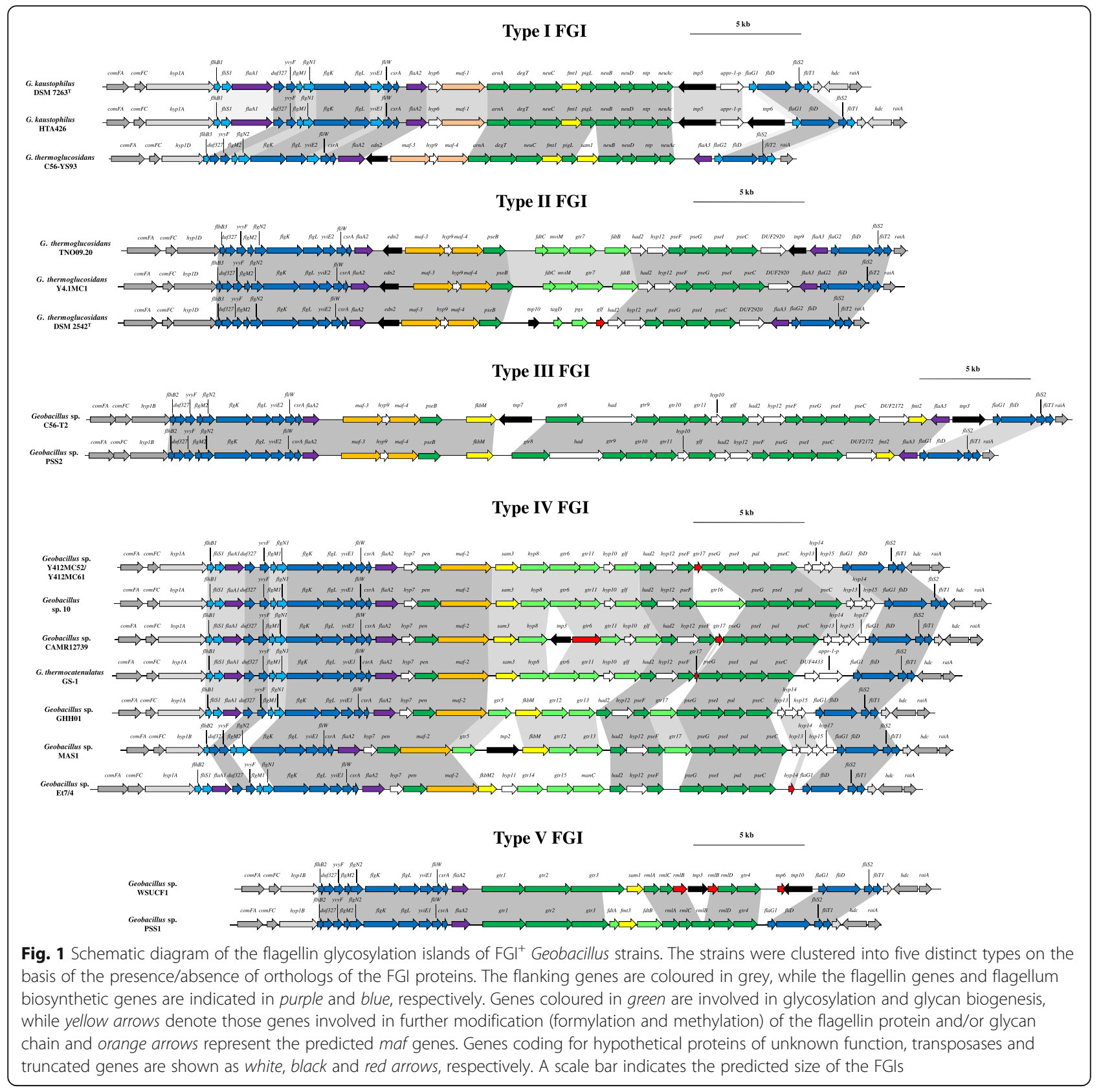

terms of the presence/absence of flagellin glycosylation islands (Fig. 3).

The flaA2-flaG intergenic region in the $\mathrm{FGI}^{-}$strains is relatively small, ranging in size from 0.9 to $6.9 \mathrm{~kb}$ (average $\mathrm{G}+\mathrm{C}$ content: $44.73 \%$; $5.18 \%$ below genome average) and coding for between zero and six CDSs (Table 1). Among the genes within this region in the $\mathrm{FGI}^{-}$strains Geobacillus sp. C56-T3, JF8 and G. caldoxylosilyticus CIC9 is a gene (edn1) coding for a LAGLIDADG family site-specific DNA endonuclease. A paralogous copy $(e d n 2)$ is also found in this region in the $\mathrm{FGI}^{-}$strain Geobacillus sp. NUB3621. This type of "homing" endonuclease catalyzes site-specific cleavage of DNA and subsequent repair by integration in the cleavage site [30]. Furthermore, a Poa1P-like macro domain (cd02901) protein (appr-1-p) is found in the $\mathrm{FGI}^{-}$strains Geobacillus sp. CAM5420 and FW23, as well as G. thermoleovorans CCB-US3_UF5 and B23, and G. kaustophilus Blys. This domain plays a role in ADP-ribosylation of proteins which effect DNA excision repair [31]. The presence of these proteins within the genomic island of $\mathrm{FGI}^{-}$strains suggests a potential mechanism of loss of FGI genes in the $\mathrm{FGI}^{-}$strains. However, copies of the genes coding for the endonuclease are also present in 


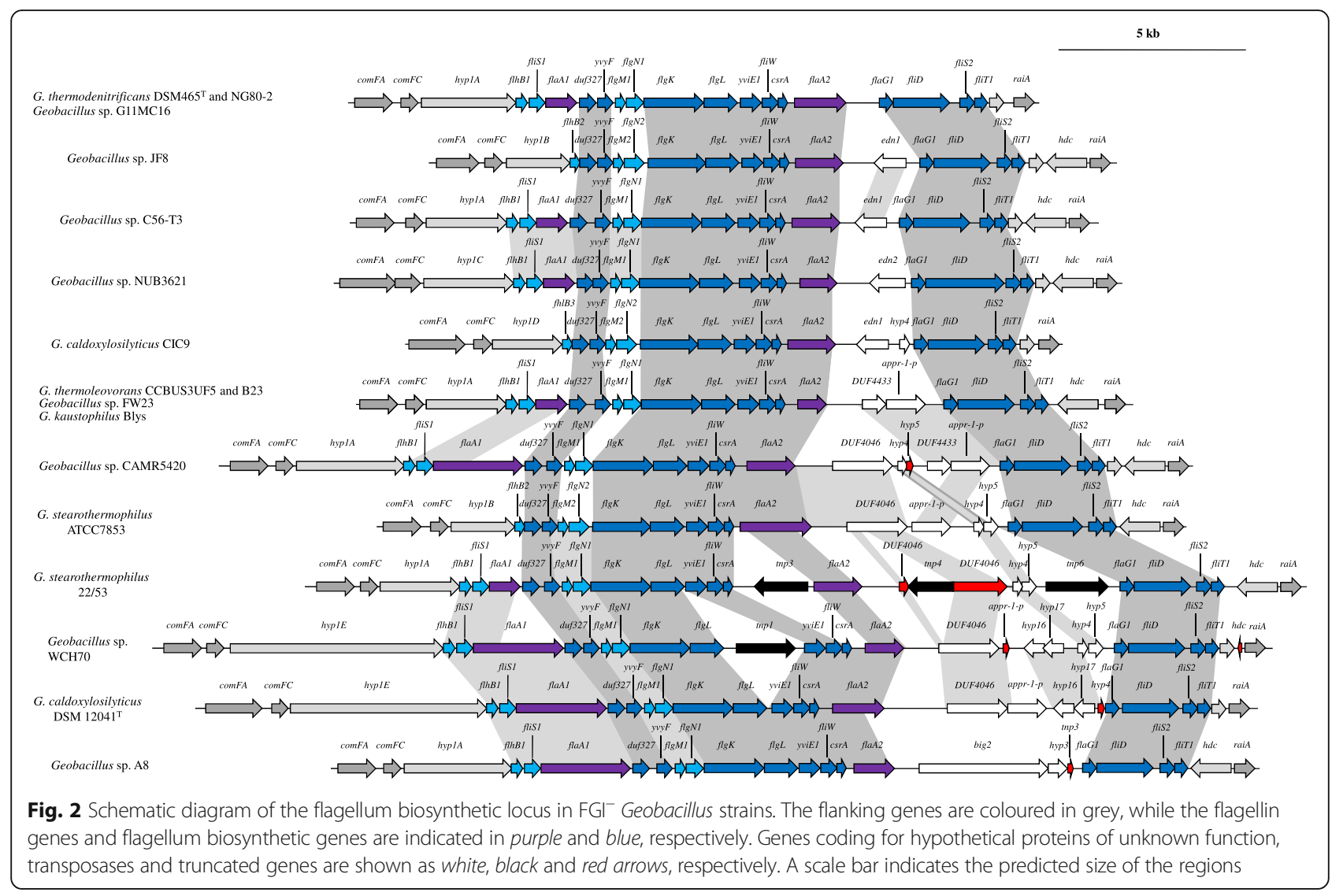

the $\mathrm{FGI}^{+}$strains G. thermoglucosidans TNO09.20 and Y4.1MC1 $(e d n 1)$ and $G$. thermoglucosidans C56YS93 and DSM $2542^{\mathrm{T}}(e d n 2)$, while orthologs of Appr-1-P are encoded in the FGIs of G. kaustophilus DSM $7263^{\mathrm{T}}$ and HTA426 and G. thermocatenulatus GS-1.

The flaA2-flaG intergenic region in the $\mathrm{FGI}^{+}$Geobacillus spp. is substantially larger than that of its $\mathrm{FGI}^{-}$counterparts, ranging in size from 13.4 to 30.4 kilobases and coding for between 11 and 23 proteins. The $\mathrm{G}+\mathrm{C}$ content (average $=40.33 \%$ ) of this FGI is on average $10.32 \%$ lower than the mean genomic $\mathrm{G}+\mathrm{C}$ content (Table 1), which indicates that this region was probably derived by horizontal acquisition.

\section{Geobacillus FGIs can be clustered into five distinct types} which correlate poorly with the recN phylogeny

Orthologs for each CDS encoded within the FGIs were identified using BlastP analyses of the CDS sets encoded on the island of the $18 \mathrm{FGI}^{+}$strains. On the basis of presence/absence of the 90 distinct CDSs encoded on the islands, a similarity matrix was constructed. This matrix was subsequently used to generate a UPGMA tree reflecting the similarity values between each of the compared $\mathrm{FGI}^{+}$strains. Using a $50 \%$ similarity cut-off value, the FGIs could be clustered into five distinct types, Types I-V (Fig. 1). The UPGMA tree was compared with a Maximum Likelihood phylogeny of the recN genes of the $18 \mathrm{FGI}^{+}$strains (Fig. 4). Only weak correlations between the FGI type and phylogeny could be observed. For example, while three of the sequenced G. thermoglucosidans strains encode Type I FGIs, G. thermoglucosidans C56-YS93 encodes a Type II FGI, while the Type V FGI-containing strains (Geobacillus sp. WSUCF1 and PSS1) are interspersed among the Type IV FGI strains in the recN phylogeny. This provides further evidence that the FGIs were derived through distinct horizontal acquisition events.

\section{Geobacillus spp. vary in both the number and type of flagellin genes}

Analysis of the Geobacillus FGI regions showed that they are flanked by up to three distinct flagellin (flaA) genes (Figs. 1 and 2), with 30 out of the 36 strains carrying two copies. One flagellin copy, flaA2 is maintained in all Geobacillus strains, both $\mathrm{FGI}^{-}$and $\mathrm{FGI}^{+}$, and is located at the 5 ' boundary of the FGIs. The FlaA2 protein is, however, highly variable, sharing only $49.01 \%$ average amino acid identity among the 36 compared strains, and ranging in length from 238 to 634 amino acids (Fig. 5a). FlaA1 is encoded on the genomes of 24 strains, including $15 \mathrm{FGI}^{-}$and nine $\mathrm{FGI}^{+}$strains (two out of three type I FGI strains and seven out of eight type IV FGI strains), 


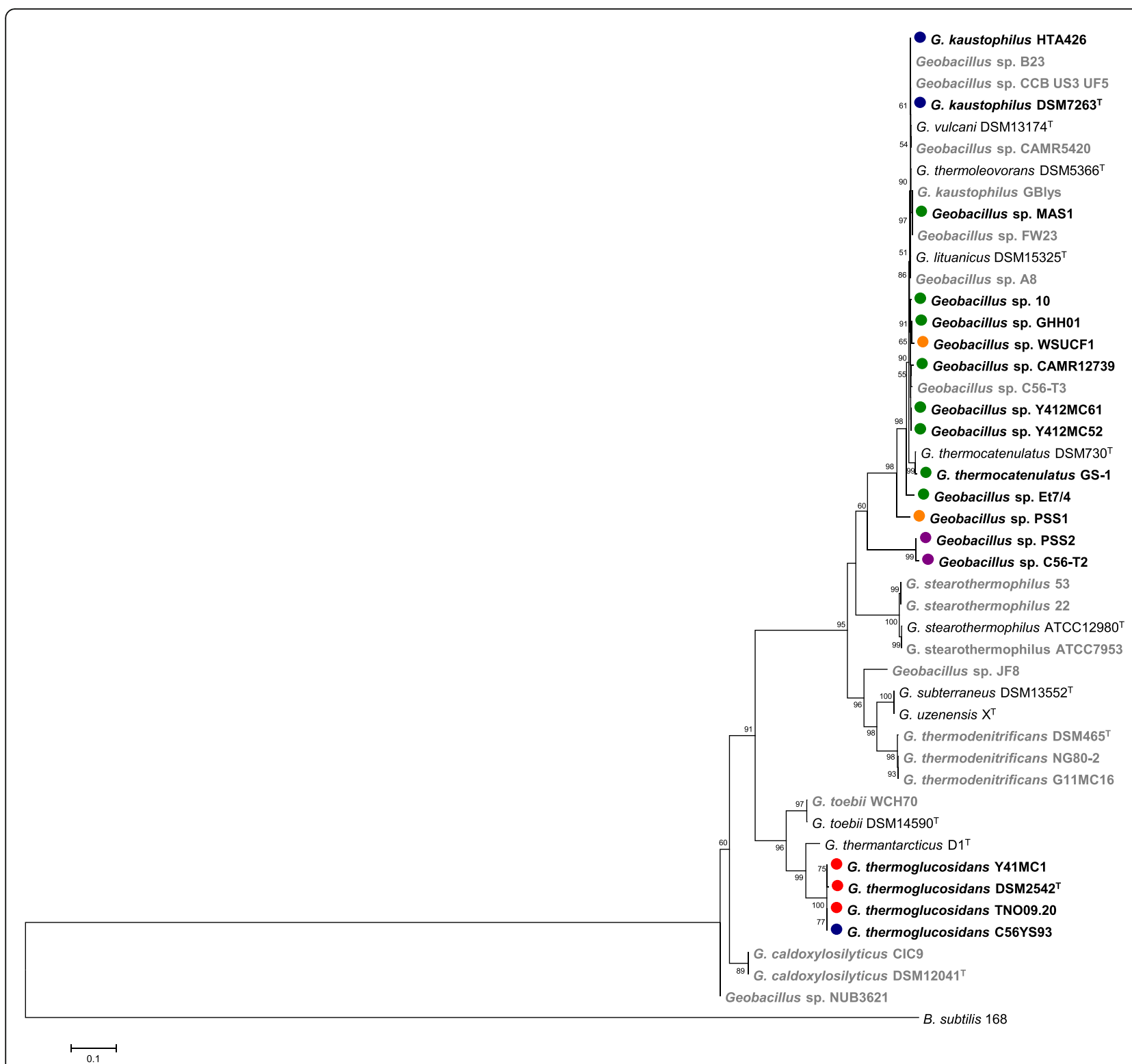

Fig. 3 recN Maximum Likelihood phylogeny of the $\mathrm{FGl}^{+}$and $\mathrm{FGl}^{-}$Geobacillus strains. Those strains in which no FGl is present are shaded in grey. The $\mathrm{FGI}^{+}$strains are indicated in bold with blue (I), red (II), purple (III), green (IV) and brown (V) dots indicating the respective group to which they belong. B. subtilis strain 168 was included as outgroup. Boot strap values $(n=1000$ replicates) are indicated

and is also highly variable, ranging in size from 275 to 799 amino acids, with an average amino acid identity of $61.92 \%$ among the 24 strains (Fig. 5b). The flaA1 gene is flanked by a second copy of fliS, which codes for a flagellin-binding chaperone that facilitates flagellin export [32], which is also absent from those strains missing flaA1. The FlaA3 proteins are similar in size (262 to 269 amino acids) and are highly conserved at the sequence level (93.84\% average amino acid identity). Alignment of the FlaA1 and FlaA2 amino acid sequences shows that extensive sequence conservation exists in both the $\mathrm{N}$ and C-termini of these proteins (Fig. 5a and b), with a highly variable central region. A similar pattern has been observed in a range of both Gram-positive and Gramnegative bacteria, with the termini of the flagellin protein being membrane bound, whereas the central region represents the surface exposed region of the protein and is under positive selective pressure $[5,33]$. No discernible pattern, in terms of protein length and sequence conservation of the FlaA1 and FlaA2 proteins, can be observed for the $\mathrm{FGI}^{+}$and $\mathrm{FGI}^{-}$strains, suggesting that the type of flagellin(s) produced is not a strict determinant of its post-translational glycosylation. By contrast, the third flagellin protein, FlaA3, is restricted to six $\mathrm{FGI}^{+}$ 
Table 1 Flagellin glycosylation island metrics

\begin{tabular}{|c|c|c|c|c|c|c|c|c|c|}
\hline Strain & Isolation source & Geographic location & $\begin{array}{l}\text { Genbank Acc. \# of } \\
\text { containing contig }\end{array}$ & FGl Type & $\begin{array}{l}\text { Genome } \\
\text { average }\end{array}$ & Island G + C\% & $\begin{array}{l}\mathrm{G}+\mathrm{C} \% \\
\text { deviation }\end{array}$ & Size (kb) & \# CDS \\
\hline G. thermodenitrificans DSM465 & Sugar beet juice & Austria & AYKT01000009 & - & $49.05 \%$ & $45.08 \%$ & $-3.97 \%$ & 0.9 & 0 \\
\hline G. thermodenitrificans G11MC16 & Grass compost & USA & ABVH01000005 & - & $48.80 \%$ & $45.77 \%$ & $-3.03 \%$ & 1 & 0 \\
\hline G. thermodenitrificans NG80-2 & Formation water of oil well & China & СР000557 & - & $49.01 \%$ & $46.30 \%$ & $-2.71 \%$ & 1.3 & 0 \\
\hline Geobacillus sp. C56-T3 & Hot Spring & Nevada, USA & CP002050 & - & $52.49 \%$ & $43.24 \%$ & $-9.25 \%$ & 1.6 & 1 \\
\hline G. caldoxylosilyticus CIC9 & Hot Spring & Indonesia & AMRO01000028/052 & - & $44.17 \%$ & $39.14 \%$ & $-5.03 \%$ & 2 & 2 \\
\hline Geobacillus sp. NUB3621 & Soil & China & AOTZ01000009 & - & $44.38 \%$ & $42.37 \%$ & $-2.01 \%$ & 2 & 1 \\
\hline Geobacillus sp. JF8 & Bark compost & Okayama, Japan & CP006254 & - & $52.87 \%$ & $46.52 \%$ & $-6.35 \%$ & 2.1 & 1 \\
\hline Geobacillus sp. FW23 & Formation water of oil well & Gujrat, India & JGCJ01000045/075 & - & $52.24 \%$ & $49.36 \%$ & $-2.88 \%$ & 3.1 & 2 \\
\hline G. thermoleovorans B23 & $\begin{array}{l}\text { Production water, subterranean } \\
\text { oil reservoir }\end{array}$ & Niigata, Japan & BATY01000075 & - & $52.29 \%$ & $49.36 \%$ & $-2.93 \%$ & 3.1 & 2 \\
\hline G. kaustophilus Blys & Hot Spring & Japan & BASG01000016 & - & $52.05 \%$ & $49.35 \%$ & $-2.70 \%$ & 3.1 & 2 \\
\hline G. thermoleovorans CCB_US3_UF5 & Hot Spring & Perak, Malaysia & CP003125 & - & $52.28 \%$ & $49.36 \%$ & $-2.92 \%$ & 3.1 & 2 \\
\hline Geobacillus sp. CAMR5420 & CAMR thermophile culture collection & University of Bath, UK & JHUS01000064 & - & $51.89 \%$ & $39.70 \%$ & $-12.19 \%$ & 4.5 & 5 \\
\hline Geobacillus sp. A8 & Deep mine water & Limpopo, South Africa & AUXP01000036 & - & $52.41 \%$ & $46.24 \%$ & $-6.17 \%$ & 5.1 & 3 \\
\hline G. stearothermophilus ATCC7953 & Underprocessed canned food & USA & JALS01000021/022 & - & $52.39 \%$ & $41.28 \%$ & $-11.11 \%$ & 5.3 & 4 \\
\hline G. toebii WCH70 & Compost & USA & CP001638 & - & $42.84 \%$ & $40.76 \%$ & $-2.08 \%$ & 5.6 & 6 \\
\hline G. caldoxylosilyticus DSM $12041^{\top}$ & Soil & Australia & BAWO01000015/16/56 & - & $43.92 \%$ & $40.33 \%$ & $-3.59 \%$ & 5.9 & 5 \\
\hline G. stearothermophilus 22 & Hot Spring & Garga, Russian Federation & JQCS01000048/070/194 & - & $52.62 \%$ & $45.46 \%$ & $-7.16 \%$ & 6.9 & 6 \\
\hline G. stearothermophilus 53 & Hot Spring & Garga, Russian Federation & JPYV01000016/113/157 & - & $52.56 \%$ & $45.46 \%$ & $-7.10 \%$ & 6.9 & 6 \\
\hline G. kaustophilus DSM $7263^{\top}$ & Pasteurized milk & USA & BBJV01000001/072 & । & $51.99 \%$ & $36.60 \%$ & $-15.39 \%$ & 14.5 & 13 \\
\hline G. thermoglucosidans C56-YS93 & Hot Spring & Obsidian, USA & CP002835 & । & $43.95 \%$ & $34.60 \%$ & $-9.35 \%$ & 15.7 & 15 \\
\hline G. kaustophilus HTA426 & Deep sea sediment & Mariana Trench & BA000043 & I & $52.09 \%$ & $38.35 \%$ & $-13.74 \%$ & 16.5 & 14 \\
\hline G. thermoglucosidans TNO09.20 & Dairy factory biofilm & Netherlands & CM001483 & $\|$ & $43.82 \%$ & $35.00 \%$ & $-8.82 \%$ & 20.6 & 18 \\
\hline G. thermoglucosidans Y4.1MC1 & Hot Spring & Yellowstone National Park, USA & CP002293 & $\|$ & $44.02 \%$ & $34.83 \%$ & $-9.19 \%$ & 20.3 & 17 \\
\hline G. thermoglucosidans DSM $2542^{\top}$ & Soil & Kyoto, Japan & BAWP01000013 & $\|$ & $43.69 \%$ & $36.16 \%$ & $-7.53 \%$ & 19.2 & 17 \\
\hline Geobacillus sp. PSS2 & Dead, steaming tree & Kilauea Volcano, Hawaii & JQMN01000001 & III & $51.58 \%$ & $36.93 \%$ & $-14.65 \%$ & 27 & 21 \\
\hline Geobacillus sp. C56-T2 & Hot Spring & Nevada, USA & GC56T2_Contig257 a & III & $52.39 \%$ & $38.95 \%$ & $-13.44 \%$ & 30.4 & 23 \\
\hline Geobacillus sp. Y412MC52 & Hot Spring & Yellowstone National Park, USA & CP002442 & IV & $52.43 \%$ & $44.58 \%$ & $-7.85 \%$ & 20.1 & 20 \\
\hline Geobacillus sp. Y412MC61 & Hot Spring & Yellowstone National Park, USA & СР001794 & IV & $52.42 \%$ & $44.58 \%$ & $-7.84 \%$ & 20.1 & 20 \\
\hline G. thermocatenulatus GS-1 & Oil well & China & JFHZ01000063 & IV & $52.11 \%$ & $45.20 \%$ & $-6.91 \%$ & 20.5 & 19 \\
\hline Geobacillus sp. CAMR12739 & CAMR thermophile culture collection & University of Bath, UK & JHUR01000060 & IV & $52.21 \%$ & $44.67 \%$ & $-7.54 \%$ & 21.2 & 22 \\
\hline Geobacillus sp. MAS1 & Hot Spring & Pakistan & AYSF01000034 & IV & $52.21 \%$ & $43.73 \%$ & $-8.48 \%$ & 21.5 & 20 \\
\hline
\end{tabular}


Table 1 Flagellin glycosylation island metrics (Continued)

\begin{tabular}{|c|c|c|c|c|c|c|c|c|c|}
\hline Geobacillus sp. 10 & Hot Spring & Yellowstone National Park, USA & CP008934 & IV & $52.71 \%$ & $43.29 \%$ & $-9.42 \%$ & 22 & 20 \\
\hline Geobacillus sp. Et7-4 & Geyser & El Tatio, Chile & JYBP01000003 & IV & $51.69 \%$ & $41.96 \%$ & $-9.73 \%$ & 18.8 & 16 \\
\hline Geobacillus sp. GHH01 & Botanical garden soil & Hamburg, Germany & CP004008 & IV & $52.28 \%$ & $43.46 \%$ & $-8.82 \%$ & 18.9 & 18 \\
\hline Geobacillus sp. WSUCF1 & Compost & Washington, USA & ATCO01000109/170/215 & V & $52.21 \%$ & $39.44 \%$ & $-12.77 \%$ & 15.8 & 13 \\
\hline Geobacillus sp. PSS1 & Dead, steaming tree & Kilauea Volcano, Hawaii & JPOI01000001 & V & $52.40 \%$ & $38.13 \%$ & $-14.27 \%$ & 13.4 & 11 \\
\hline
\end{tabular}

The sizes of the genomics islands for the $\mathrm{FGl}^{-}$and $\mathrm{FGI}^{+}$strains are indicated, as are the number of proteins (CDS) encoded in each and the difference in $\mathrm{G}+\mathrm{C}$ content (\%) from the genomic average. ${ }^{\text {a denotes the }}$ contig as per the Integrated Microbial Genome Database project (IMG ID 250801004) from which the data was obtained. The environmental source and geographical location from which each of the strains was isolated are indicated 


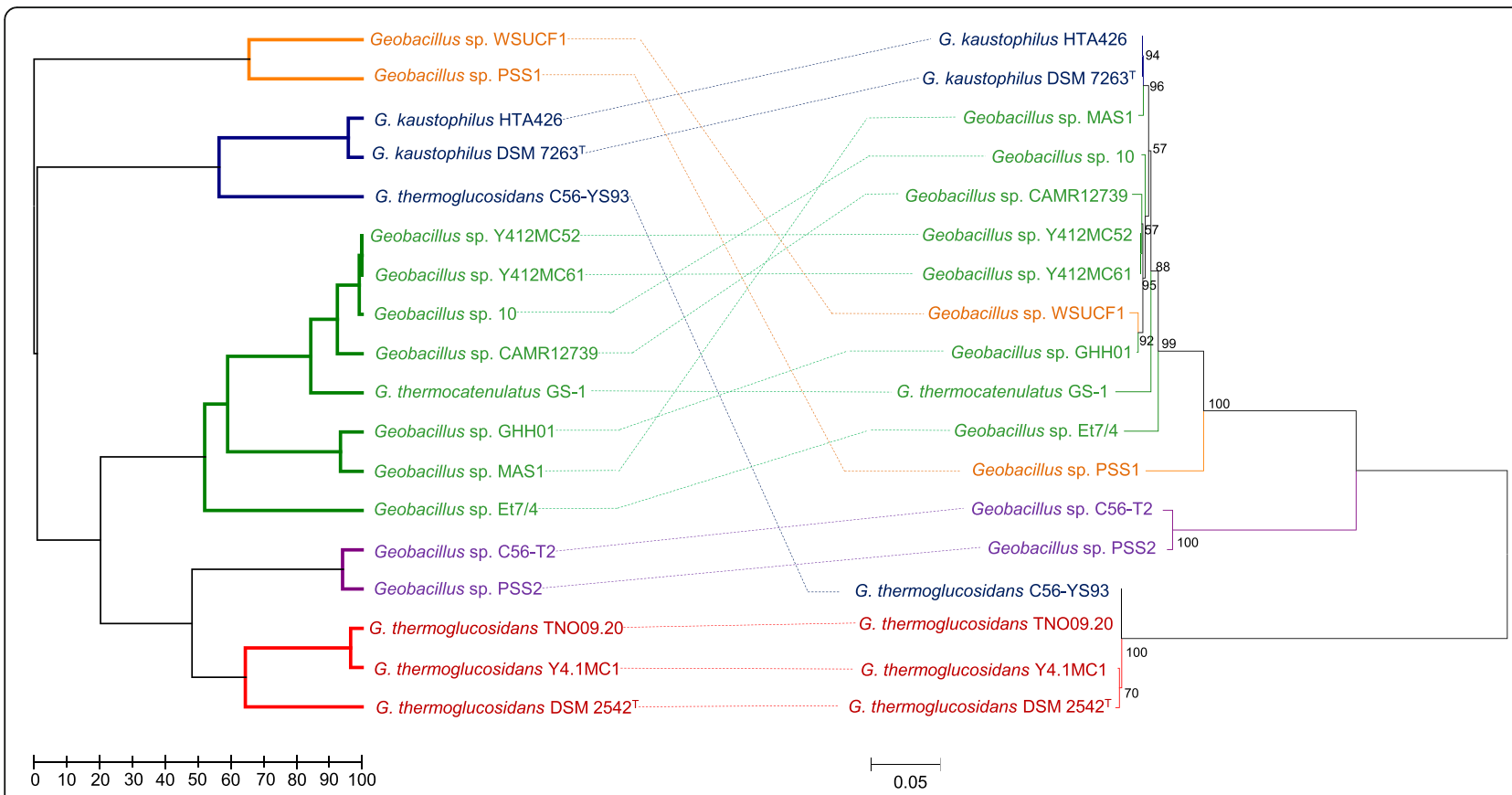

Fig. 4 FGl typing dendrogram. A UPGMA dendrogram calculated on the basis of the presence/absence of FGl proteins is shown on the left, while a recN Maximum Likelihood phylogeny is shown on the right, with the branch and taxa colours reflecting the FGl types indicated in Fig. 3. Boot strap values ( $n=1000$ replicates) are indicated

strains, including one Type I, three Type II and two Type III FGI strains (Fig. 5c). The presence of flaA3 in strains with three different types of FGI, and the presence of this gene in only one of three strains with Type I FGI suggests, however, that this flagellin gene alone does not dictate its post-translational modification with a particular glycan.

The presence of two distinct flagellin genes in 30 of the analysed Geobacillus strains indicates that strains of this species may be capable of flagellin phase variation. This process has been observed in a number of Gramnegative pathogens including Campylobacter jejuni, Salmonella enterica and Escherichia coli, where two antigenically distinct flagellin genes are alternatively expressed [27, 34, 35]. As flagellin proteins represent potent antigens which can serve as a trigger for innate immune responses in both plant and animals, the phasevariable expression of a distinct flagellin can allow a pathogen to temporarily avoid cellular immunity [34-36]. Whether Geobacillus spp. are capable of phase variable expression of the distinct flagellin genes and the potential biological role of this trait in these environmental bacteria remains to be functionally determined.

The Geobacillus FGls carry genes for several distinct glycan biosynthetic pathways

Nineteen distinct glycosyltransferases (gtr1-gtr18 and $\operatorname{man} C)$ are encoded within the flagellin glycosylation islands among the $18 \mathrm{FGI}^{+}$strains, with up to five distinct glycosyltransferases (Type III FGI strains Geobacillus sp. C56-T2 and PSS2) in the individual strains. The glycosyltransferases were classified into their respective Glycosyl Transferase families using the dbCAN Blast tool [37, 38]. Ten of the FGI glycosyltransferases belong to the GT2 family, eight to the GT4 family, while Gtr16 could not be classified in a particular family (GT0). Both the GT2 and GT4 family have transferase activities for a wide range of target sugars; and thus, the type of glycan transferred to the flagellin proteins can therefore not be inferred on the basis of glycosyltransferase type alone. One exception is the mannose-1phosphate guanylyltransferase in the Type IV FGI strain Geobacillus sp. Et7/4, which shares $64.93 \%$ amino acid identity with the ManC enzyme in the S-layer glycosylation locus of Aneurinibacillus thermoaerophilus L420-91 ${ }^{\mathrm{T}}$ (AAS55729.1), suggesting the flagellin in Geobacillus Et7/ 4 is mannosylated. With the exception of the Type V FGI strains, the remaining $16 \mathrm{FGI}^{+}$strains encode four distinct Maf proteins. One Maf protein is found in two of the type I FGI strains, G. kaustophilus DSM $7263^{\mathrm{T}}$ and HTA426 (maf1) and the eight type IV FGI strains (maf4). By contrast, the type I FGI strain G. thermoglucosidans C56YS93 and all type II and III FGI strains encode two Maf proteins (maf2 and maf3). If, as is predicted to be the case in A. caviae [9], these maf genes encode glycosyltransferases with unknown glycan substrates, this further confounds the roles of the distinct glycosyltransferases in Geobacillus flagellin glycosylation. However, a variety of 


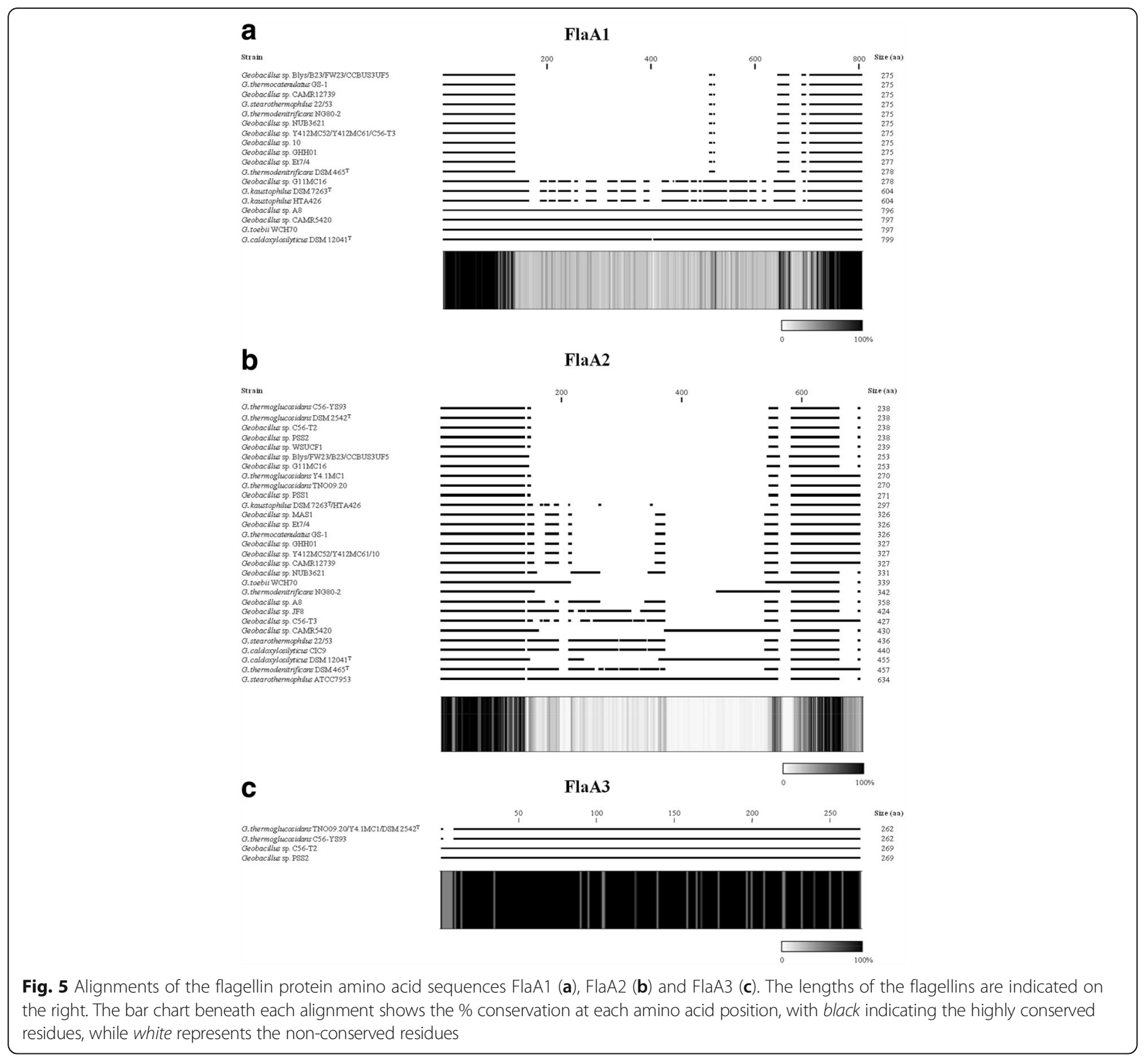

enzymes for the biosynthesis of distinct sugars are encoded in the FGIs and, on this basis, some predictions on the putative sugar constituents of the Geobacillus flagellin glycans could be made.

The Type I FGIs encode orthologs of four proteins involved in the biosynthesis of $N$-acetyl neuraminic acid (NeuAc). NeuAc belongs to the nonulosonic acids, a diverse family of acidic nine-carbon backbone monosaccharides which also includes pseudaminic (Pse) and legionamic (Leg) acids [39]. NeuAc is incorporated in the polysialic capsule of $E$. coli, the lipo-oligosaccharide (LOS) of Campylobacter jejuni and LPS of Leptospira spp. [40, 41], but has not been observed as part of flagellin glycans. By contrast, Pse is frequently found as part of flagellin glycans, including in Campylobacter and
Helicobacter spp. [7], and legionamic acid forms part of the glycans associated with the flagellins of Campylobacter spp. and Clostridium botulinum [19]. The UDP-GlcNAc 2-epimerase $\mathrm{NeuC}$ initiates the conversion of UDPGlcNAc to ManNAc. Subsequently, NeuB condenses ManNAc and phosphoenolpyruvate before CMP-NeuNAc synthetase (NeuAc) activates the $N$-acetyl-neuraminic sugar $[42,43]$. While the function of the fourth protein, the acetyltransferase NeuD, is unknown, it is predicted to play a role in the stabilisation of NeuB [42, 43]. The NeuAcBCD proteins encoded in the type I FGIs of $G$. kaustophilus DSM $7263^{\mathrm{T}}$ and HTA426, and G. thermoglucosidans C56-YS93 share $47.98 \%$ average amino acid identity with their orthologs in the E. coli H708b O-antigen cluster (BAQ01507-1512) [44]. Interspersed among the 
Type I FGI neuCBDA genes are genes encoding an NADdependent epimerase $(\operatorname{arn} A)$, an aminotransferase $(\operatorname{deg} T)$ and a nucleotidyltransferase ( $n t p)$. This has also been observed in Leptospira interrogans and these are predicted to be involved in the synthesis of neuraminic acid [45].

The Type II, III and IV FGIs (13 Geobacillus strains) contain genes coding for enzymes involved in the synthesis of 5,7-diacetamido-3,5,7,9-tetadeoxy-L-glycero- $\alpha$ L-manno-nonulosonic acid (pseudaminic acid - Pse). The Pse biosynthetic pathway involves six enzymes. A bi-functional 4,6-dehydratase/5-epimerase (PseB) converts UDP-D-GlcNAc to UDP-4-keto-6-deoxy-L-AltNAc which is subsequently aminated at $\mathrm{C} 4$ by aminotransferase $\mathrm{PseC}$ and $N$-acetylated by the $N$-acetyltransferase $\mathrm{PseH}$ to form 2,4,6-tridoxy-2,4-NAc-L-altrose. UDP is cleaved from the sugar by UDP-sugar hydrolase PseG and it is pyruvylated by the pseudaminic acid synthase PseI. Finally, the cytidylyltransferase PseF adds cytidine monophosphate to produce the final CMP-Pse product [46-48]. With the exception of the $N$-acetyltransferase PseH, orthologs of four CMP-Pse biosynthetic enzymes (PseC, PseF, PseG and PseI) are encoded in the FGIs of all Type II, III and IV Geobacillus strains. These proteins share $52.69 \%$ average amino acid identity with PseC in the FGI of Bacillus thuringiensis subsp. israelensis ATCC35646 (RBTH_04255-4259), where they are likewise involved in biosynthesis of the pseudaminic acid precursor of the flagellin glycan [47]. In the Type II and III FGI strains, a gene coding for the bi-functional dehydratase/epimerase PseB (59.92\% average amino acid identity to C. jejuni CJ1293) is present at the $5^{\prime}$ end of the FGI. In B. thuringiensis ATCC356464, the initial conversion step of UDP-GlcNAc to UDP-4-keto-6-deoxy-L-AltNAc catalysed by PseB in Campylobacter and Helicobacter spp. is undertaken by two distinct enzymes, a UDP-GlcNAc 4-oxidase/5,6-dehydrogenase/4 reductase (Pen) and a UDP-6-deoxy-D-GlcNAc-5,6-ene 4oxidase/5,6-reductase/-5-epimerase (Pal) [47]. Orthologs of Pen and Pal (RBTH_04253-4255: 66.0\% average amino acid identity) are present in the FGIs of the Type IV FGI strains. The pen gene is localized at the $5^{\prime}$ end of the Type IV FGI, while pal is located near the 3' end, in contrast to the pseudaminic acid biosynthetic locus in $B$. thuringiensis ATCC35646, where they are found adjacent to each other (Additional file 1: Figure S1). Alignment of the Geobacillus FGIs against the partial flagellin glycosylation locus of C. jejuni 81-176 (AY102662) also demonstrates extensive rearrangement of the pseudaminic acid biosynthetic genes within the Geobacillus FGIs (Additional file 1: Figure S1). A phylogeny constructed on the basis of the concatenated PseI and PseC protein sequences, reflects the distinct clustering of the pseBcontaining (Type II and III FGI) and pen and pal-containing (Type IV FGI) loci. This suggests that, although the Geobacillus FGI pseudaminic acid biosynthetic proteins are more similar to each other than those encoded in the loci of B. thuringiensis ATCC35646 and C. jejuni $81-176$, they may have distinct evolutionary origins and may have been derived through distinct horizontal gene transfer events (Additional file 2: Figure S2).

The Type V FGI strains Geobacillus sp. WSUCF1 and PSS1 encode orthologs of the glucose-1-phosphate thymidylyltransferase RmlA, thymidine diphosphate (dTDP)glucose 4,6 dehydratase RmlB, dTDP-4-dehydrorhamnose 3,5-epimerase RmlC and dTDP-dehydrorhamnose reductases RmlD which together catalyse the sequential conversion of dTDP-D-glucose to dTDP-L-rhamnose [49], suggesting that the flagellin proteins in these strains are rhamnosylated. However, in Geobacillus sp. WSUCF1 the $r m l B$ reading frame is disrupted by a transposon insertion (Fig. 1). The RmlABCD protein products of WSUCF1 (96.69\% average amino acid identity) and PSS1 (79.24\% average amino acid identity) share extensive sequence identity with the $\operatorname{rm} A B C D$ protein products responsible for glycosylation of the S-layer protein SgsE in G. stearothermophilus NRS2004/3a (AAR99610.1-613.1) [49]. This suggests genetic interchange between the glycan biosynthetic pathways for glycosylation of the two distinct surface components, the S-layer and flagellin proteins, may have occurred.

The FGI of Geobacillus sp. PSS1 also encodes orthologs of dTDP-6-deoxy-3,4-keto-hexulose isomerase (FdtA) and transaminase (FdtB). These enzymes catalyze the conversion of dTDP-6-deoxy-D-xylohex-4-ulose generated by RmlA and RmlB to dTDP-3-oxo-6-deoxy-D-galactose [50]. The Geobacillus sp. PSS1 proteins share $64.62 \%$ average amino acid identity with FdtA (AAS55720) and FdtB (AAS55722) in Aneurinibacillus thermoaerophilus L420$91^{\mathrm{T}}$. In the latter strain, a third enzyme, FdtC, catalyzes the transfer of an acetyl group to dTDP-D-Fucp3N to form dTDP-D-Fuc3pNAc, which along with D-rhamnose forms the repeating unit of the S-layer glycan chain [50]. Orthologs of FdtB (44.41\% amino acid identity to AAS55722), as well as the acetylase FdtC (AAS55722: 47.98\% amino acid identity) are also found in the type II FGI strains G. thermoglucosidans Y4.1MC1 and TNO09.20. The absence of an ortholog of the isomerase FdtA suggests the FdtB and FdtC orthologs in these strains catalyse the transamination and acetylation of a distinct sugar, while the absence of FdtC orthologs in PSS1 suggests that the dTDP-3-oxo-6deoxy-D-galactose of this strain is not acetylated.

Orthologs of the UDP-galactopyranose mutase (Glf), which catalyzes the conversion of UDP-galactose from its pyranose to its furanose form [51], are encoded in both Type III and five of the eight Type IV FGI strains. A partial $g l f$ gene is also encoded in the Type II FGI of G. thermoglucosidans DSM $2542^{\mathrm{T}}$. Galactofuranose is found in the O-antigens of E. coli and Klebsiella 
pneumoniae, in the arabinogalactan main structural polymer in the Mycobacterium tuberculosis cell wall and the S-layer glycan of Thermoanaerobacterium thermosaccharolyticum [51, 52]. In the FGI region containing the $f d t C$ and $f d t B$ genes in the type II FGI strains G. thermoglucosidans TNO09.20 and Y4.1MC1, G. thermoglucosidans DSM $2542^{\mathrm{T}}$ instead contains two genes, tagD and pgs, coding for a glycerol-3-phosphate cytidylyltransferase and a phosphatidylylglycerophosphate synthase (Pgs). The former enzyme converts sn-glycerol-3phosphate to CDP-glycerol (E.C. 2.7.7.39), while Pgs catalyzes the conversion of CDP-diacylglycerol to phosphatidylglycerophosphate (E.C. 2.7.8.5) [53, 54]. The presence of these two key enzymes of phospholipid biosynthesis suggests that the flagellin in this strain may be modified with a phospholipid derivative. Lipid modification of surface proteins has only been identified in three haloarchaeal species to date; Halifax volcanii, Halobacterium salinarum and Haloarcula japonica [55]. Lipid modification of the flagellin in G. thermoglucosidans DSM $2542^{\mathrm{T}}$ would, however, need to be confirmed experimentally.

\section{The Geobacillus FGls show evidence of further glycan modifications}

Aside from the distinct sugars observed in the glycans of the various flagellin-glycosylated bacterial taxa, the flagellin proteins and their glycan sugars are frequently heavily modified by formyl, methyl and acetyl groups [14]. While the biological functions of these modifications and the resultant structural diversity of the flagellin proteins and their glycans remain largely obscure, they may influence the functioning and roles of the flagellum [14]. Three distinct S-adenosylmethionine-dependent methyltransferases are encoded in the Geobacillus FGIs. The sam1 gene in the Type I FGI of G. thermoglucosidans C56-YS93 is localised in the middle of the neuraminic acid biosynthetic locus, suggesting the encoded methyltransferase is responsible for methylation of this sugar. Five out of the eight type IV FGI strains contain a distinct methyltransferase (sam2), while sam3 is located just upstream of the rhamnosyl biosynthetic genes of Geobacillus sp. WSUCF1 (Type V FGI). Methyltransferases of the FkbM family ( $f k b M 1)$ are also present in the type III FGI strains Geobacillus sp. C56-T2 and PSS2, as well as the Type IV FGI strains Geobacillus sp. GHH01 and MAS1. A distinct FkbM-type methyltransferase ( $f k b M 2)$ showing weak homology to $f k b M 1$ (30.80\% average amino acid identity) is also encoded in the Type IV FGI strain Geobacillus sp. Et7/4. Methylated flagellin glycans have also been observed in the phytopathogen Pseudomonas syringae (rhamnosyl) and Clostridium botulinum (legionamic acid derivative) [19, 56]. The presence of two distinct families of methyltransferases in
15 of the $18 \mathrm{FGI}^{+}$strains suggests that flagellin and/or glycan methylation is an important feature of the flagella of Geobacillus spp. Formyltransferases are encoded in the flagellin glycosylation island of Alteromonas macleodii AltDE1 [57]. Similarly, three distinct formyltransferase genes are found in the three type I FGI strains $(f m t 1)$, both type III FGI strains ( $f m t 2)$ and one type V FGI strain (fmt3). The fmt3 gene in Geobacillus PSS1 occurs in the location occupied by the acetyltransferase gene $f d t C$ in other dTDP-3-oxo-6-deoxy-D-galactose synthesising bacteria, suggesting that this sugar is formylated, rather than acetylated in Geobacillus sp. PSS1. The form and functions of the modifications derived by formylation and methylation of the flagellin proteins and/or the glycan chains in Geobacillus spp. remain to be structurally and functionally elucidated.

\section{Conclusions}

Using comparative genomic approaches, we have identified and characterized the flagellin glycosylation islands in eigtheen Geobacillus strains for which genome sequences are available. These islands code for highly variable flagellin glycans comprising of several distinct sugar derivatives, which appear to be extensively diversified by the addition of methyl, acetyl and formyl groups. Extensive hallmarks of horizontal gene transfer, including divergent $G+C$ contents and the presence of transposase and endonuclease genes, are present, suggesting that the versatility of these loci may be linked to their horizontal acquisition from distinct microbial origins.

The presence of FGIs in only half of the 36 compared Geobacillus strains raises questions on the functional roles of these glycans in members of this genus. Flagellin glycosylation is essential for flagellar filament formation and swimming motility in a range of Gram-negative bacterial taxa, as well as the Gram-positive relative Paenibacillus alvei $[7,8,13]$. The original descriptive publications of the genus Geobacillus indicated that the type strains of all the described species are all motile. This includes both $G$. thermodenitrificans DSM $465^{\mathrm{T}}$ [20] and G. caldoxylosilyticus DSM $12041^{\mathrm{T}}$ [58], which we have here shown lack FGI loci, suggesting that flagellin glycosylation is not a prerequisite for flagellum biogenesis and motility for members of this genus. This, however, assumes that the $\mathrm{FGI}^{-}$and $\mathrm{FGI}^{+}$Geobacillus strains compared differ only in terms of flagellin glycosylation. However, it should not be precluded that additional differences, such as differences in other flagellum biosynthetic genes, the differences in flagellin protein lengths and sequence homology among the $\mathrm{FGI}^{-}$and $\mathrm{FGI}^{+}$strains, may be contributing factors in filament biogenesis and flagellar motility.

In some Archaea, protein glycosylation is not essential for survival, but may make an adaptive contribution to survival in harsh environments [18]. Flagellin glycosylation 
was observed to increase the stability of flagellin proteins under heat treatment in the phytopathogen P. syringae pv. tabaci, while N-glycosylation of the Bacillus amyloliquefaciens (1,3-1,4)-beta glucanase was also shown to improve thermostability of this enzyme $[17,59]$. The contribution of flagellin glycosylation to the thermostability of the flagellin protein in Geobacillus spp. is an attractive hypothesis. However, the temperature optima of both the $\mathrm{FGI}^{+}$and $\mathrm{FGI}^{-}$Geobacillus strains suggest a function for flagellin glycosylation other than thermostability. A large number of additional functions have been elucidated or hypothesised for flagellin glycosylation, including surface recognition, attachment, host defense avoidance and increased resistance against proteolytic cleavage [16]. Further analyses, such as knock-out mutagenesis and functional characterization of the flagellin protein and its glycan chain are needed to determine the function of flagellin glycosylation in members of the genus Geobacillus.

\section{Methods}

\section{Characterisation of the flagellin glycosylation island loci}

The flanking genes (comFA - BSU35470 and raiA BSU35310) for the flagellar biosynthetic locus of Bacillus subtilis 168 (NC_000964.3) were used to identify the orthologous flagellum biosynthetic loci in the genomes of 36 Geobacillus isolates (Table 1). The loci were extracted from the genome sequences, open reading frames were predicted using GeneMark.hmm [60] and the $\mathrm{G}+\mathrm{C}$ contents of the FGIs were determined using Bioedit v. 7.1.11 [61]. The proteins encoded on the FGIs were functionally annotated by BlastP comparison against the NCBI non-redundant (nr) protein database to identify orthologs in other bacterial taxa for which functional data is available. Orthology was assumed for those proteins sharing $>50 \%$ amino acid identity over $70 \%$ of the protein length. Further support for the protein function was obtained by identifying conserved functional domains through comparison of the proteins against the Conserved Domain Database using Batch CD-search [62]. Orthology among the proteins for the Geobacillus FGI datasets was determined using BlastP analyses in BioEdit [61] using the orthology criteria of $>70 \%$ amino acid identity over $70 \%$ of the protein length.

\section{Phylogeny construction}

Phylogenies were constructed on the basis of the $\operatorname{recN}$ house-keeping gene coding for the DNA repair protein $\mathrm{RecN}$ and the concatenated PseC and PseI amino acid sequences. Sequences were aligned using the MAFFT v. 7 alignment server [63] with default parameters. The recN Maximum Likelihood trees were constructed with the Molecular Evolutionary Genetics Analysis (MEGA) v. 7.0.14 software package [64], using the Tamura-Nei evolutionary model, complete gap deletion, nearest-neighbour- interchange ML heuristic method and bootstrap analysis $(n=1000)$. The concatenated PseC and PseI amino acid Maximum Likelihood phylogeny was likewise constructed with MEGA v 7.0.14 [64], using the Jones-Taylor-Thornton model, complete gap deletion, nearest-neighbourinterchange ML heuristic method and bootstrap analysis $(n=1000)$. A dendrogram was constructed on the basis of the presence/absence of orthologs for each of the FGI proteins among the $\mathrm{FGI}^{+}$strains. Present orthologs were scored with a 1, while absent orthologs, as well as truncated and transposon-disrupted proteins were scored as a 0 . The resultant matrix was used to generate a distance matrix using Bionumerics v 6.6 (Applied Maths N.V., Belgium) using absolute values and Pearson's correlation. The distance matrix was used to generate an Unweighted Pair Group Method with Arithmetic Mean (UPGMA) dendrogram using Phylip v. 3.69 [65]. Similarity cut-off values of $50 \%$ were used to distinguish between the FGI types.

\section{Additional files}

Additional file 1: Figure S1. Schematic diagram of the pseudaminic acid biosynthetic gene-containing FGls. The pseudaminic acid biosynthetic genes are indicated in green. Flanking genes are indicated as white and yellow arrows. A scale bar indicates the predicted size of the regions. (PDF $23 \mathrm{~kb}$ )

Additional file 2: Figure S2. Maximum Likelihood phylogeny of the concatenated pseudaminic acid biosynthetic proteins PseC and Psel. Boot strap values ( $n=1000$ replicates) are indicated. (PDF $8 \mathrm{~kb}$ )

Abbreviations

CDS: Protein coding sequence; FGl: Flagellin glycosylation island

\section{Acknowledgements}

Not applicable.

Funding

PDM was funded by the National Research Foundation of South Africa (Research Career Advancement Fellowship - Grant 91447).

\section{Availability of data and materials}

The datasets generated and/or analyzed during this study, including sequences of the FGI regions, sequence alignments, newick trees, and distance matrices are available in the LabArchives repository (https://mynotebook.labarchives.com/ share/Geobacillus_FGI_Manuscript/MC4wfDE4OTc2NS8wL1RyZWWOb2RILZM2O TEzMTlyMDh8MC4w) [66]. The phylogenies included in the manuscript (Figs. 3 and 4 and Additional file 2: Figure S2) have been deposited and are available in TreeBASE (http://purl.org/phylo/treebase/phylows/study/TB2:S20124) [67].

\section{Authors' contributions}

PDM and DAC conceived the study. PDM performed experiments and analyses. PDM and DAC wrote the original manuscript. Both authors have read and approved the final version.

\section{Competing interests}

The authors declare that they have no competing interests.

Consent for publication

Not applicable.

Ethics approval and consent to participate

Not applicable. 


\section{Author details}

'School of Molecular and Cell Biology, University of the Witwatersrand, Private Bag 3, Wits, 2050, Johannesburg, South Africa. ${ }^{2}$ Centre for Microbial Ecology and Genomics, Genomics Research Institute, University of Pretoria, Pretoria 0002, South Africa.

Received: 26 July 2016 Accepted: 5 November 2016

Published online: 14 November 2016

\section{References}

1. Abu-Qarn M, Eichler J, Sharon N. Not just for Eukarya anymore: protein glycosylation in Bacteria and Archaea. Curr Opin Struct Biol. 2008;18:544-50.

2. Benz I, Schmidt MA. Never say never again: protein glycosylation in pathogenic bacteria. Mol Microbiol. 2002:45:267-76.

3. Merino S, Tomás JM. Gram-negative flagella glycosylation. Int J Mol Sci. 2014;15:2840-57.

4. Hayakawa J, Ishizuka M. Flagellin glycosylation: current advances. In: Petrescu S, editor. Glycosylation. Rijeka, Croatia: InTech Publishers; 2012. p. 127-52.

5. Beatson SA, Minamino T, Pallen MJ. Variation in bacterial flagellins: from sequence to structure. Trends Microbiol. 2006;14:151-5.

6. Hayakawa J, Kambe T, Ishizuka M. Amino acid substitutions and intragenic duplications of Bacillus sp. PS3 flagellin cause complementation of the Bacillus subtilis flagellin deletion mutant. Biosci Biotechnol Biochem. 2009;73:2348-51.

7. Logan SM. Flagellar glycosylation - a new component of the motility repertoire? Microbiol. 2006;152:1249-62.

8. Janesch B, Schirmeister F, Maresch D, Altmann F, Messner P, Kolarich D, et al. Flagellin glycosylation in Paenibacillus alvei CCM $2051^{\top}$. Glycobiol. 2016;26:74-87.

9. Parker JL, Day-Williams MJ, Tomás JM, Stafford GP, Shaw JG. Identification of a putative glycosyltransferase responsible for the transfer of pseudaminic acid onto the polar flagellum of Aeromonas caviae Sch3N. Microbiol Open. 2012;1:149-60

10. Szymanski CM, Logan SM, Linton D, Wren BW. Campylobacter - a tale of two protein glycosylation systems. Trends Microbiol. 2003;11:233-8.

11. Schirm M, Arora SK, Verma A, Vinogradov E, Thibault P, Ramphal R, et al. Structural and genetic characterization of glycosylation of type a flagellin in Pseudomonas aeruginsa. J Bacteriol. 2004;186:2523-31.

12. Takeuchi K, Taguchi F, Inagaki Y, Toyoda K, Shiraishi T, Ichinose Y. Flagellin glycosylation island in Pseudomonas syringae pv. glycinea and its role in host specificty. J Bacteriol. 2003;185:6658-6665.

13. De Maayer P, Cowan D. Flashy flagella: flagellin modification is relatively common and highly versatile among the Enterobacteriaceae. BMC Genomics. 2016;17:377.

14. Nothaft H, Szymanksi CM. Protein glycosylation in bacteria: sweeter than ever. Nat Rev Microbiol. 2010;8:765-78.

15. Howard SL, Jagannathan A, Soo EC, Hui JPM, Aubry AJ, Ahmed I, et al. Campylobacter jejuni glycosylation island improtant in cell charge, legionaminic acid biosynthesis, and colonization of chickens. Infect Immun. 2009:77:2544-56.

16. Schmidt MA, Riley LW, Benz I. Sweet new world: glycoproteins in bacterial pathogens. Trends Microbiol. 2003:11:554-61.

17. Taguchi F, Suzuki T, Takeuchi K, Inagaki Y, Toyoda K, Shiraishi T, et al. Glycosylation of flagellin from Pseudomonas syringae pv. tabaci 6605 contributes to evasion of host tobacco plant surveillance system. Physiol Mol Plant Pathol. 2009;74:11-7.

18. Calo D, Kaminski L, Eichler J. Protein glycosylation in Archaea: sweet and extreme. Glycobiol. 2010;20:1065-76.

19. Twine SM, Paul CJ, Vinogradov E, McNally DJ, Brisson J-R, Mullen JA, et al. Flagellar glycosylation in Clostridium botulinum. FEBS J. 2008;275:4428-44.

20. Coorevits A, Dinsdale A, Halket G, Lebbe L, De Vos P, Van Landschoot A, et al. Taxonomic revision of the genus Geobacillus: emendation of Geobacillus, G. stearothermophilus, G. jurassicus, G. toebii, G. thermodenitrificans and G. thermoglucosidans (nom. corrig., formerly 'thermoglucosidasius'); transfer of Bacillus thermantarcticus to the genus as G. thermantarcticus comb. nov.; proposal of Caldibacillus debilis gen. nov., comb. nov.; transfer of $G$. tepidamans to Anoxybacillus as A. tepidamans comb. nov.; and proposal of Anoxybacillus caldiproteolyticus sp. nov. Int J Syst Evol Microbiol. 2012;62:1470-85

21. Hussein AH, Lisowska BK, Leak DJ. The genus Geobacillus and their biotechnological potential. Adv Appl Microbiol. 2015;92:1-48.

22. Zeigler DR. The Geobacillus paradox: why is a thermophilic bacterial genus so prevalent on a mesophilic planet? Microbiol. 2014;160:1-11.
23. Hayakawa J, Kondoh Y, Ishizuka M. Cloning and characterization of flagellin genes and identification of flagellin glycosylation from thermophilic Bacillus species. Biosci Biotechnol Biochem. 2009;73:1450-2.

24. Langille MGl, Brinkman FSL. IslandViewer: an integrated interface for computation identification and visualization of genomic islands. Bioinf. 2009;25:664-5.

25. Macnab RM. Genetics and biogenesis of bacterial flagella. Ann Rev Genet. 1992;26:131-58.

26. Canals R, Vilches S, Wilhelms M, Shaw JG, Merino S, Tomás JM. Non-structural flagella genes affecting both polar and lateral flagella-mediated motility in Aeromonas hydrophila. Microbiol. 2007;153:1165-75.

27. Karlyshev AV, Linton D, Gregson NA, Wren BW. A novel paralogous gene family involved in phase-variable-flagella-mediated motility in Campylobacter jejuni. Microbiol. 2002;148:473-80.

28. Zeigler DR. Application of a recN sequence similarity analysis to the identification of species within the bacterial genus Geobacillus. Int J Syst Evol Microbiol. 2005;55:1171-9.

29. Zeigler DR. Gene sequences useful for predicting relatedness of whole genomes in bacteria. Int J Syst Evol Microbiol. 2003;53:1893-900.

30. Dalgaard JZ, Klar AJ, Moser MJ, Holley WR, Chatterjee A, Mian IS. Statistical modeling and analysis of the LAGLIDADG family of site-specific endonucleases and identification of an intein that encodes a site-specific endonuclease of the HNH family. Nucleic Acids Res. 1997;25:4626-38.

31. Rouleau M, Aubin R, Poirier G. Poly(ADP-ribosyl)ated chromatin domains: access granted. J Cell Sci. 2004;117:815-25.

32. Galeva A, Moroz N, Yoon Y-H, Hughes KT, Samatey FA, Kostyukova AS. Bacterial flagellin-specific chaperone FliS interacts with anti-sigma faqctor FlgM. J Bacteriol. 2014;196:1215-21.

33. Wang L, Rothermund D, Curd H, Reeves PR. Species-wide variation in the Escherichia coli flagellin (H-antigen) gene. J Bacteriol. 2003;185:2936-43.

34. Bonifield HR, Hughes KT. Flagellar phase variation in Salmonella enterica is mediated by a postranscriptional control mechanism. J Bacteriol. 2003:185:3567-74

35. Feng L, Liu B, Liu Y, Ratiner YA, Hu B, Li D, et al. A genomic islet mediates flagellar phase variation in Escherichia coli strains carrying the flagellinspecifying locus flk. J Bacteriol. 2008;190:4470-7.

36. van der Woude MW, Bäumler AJ. Phase and antigenic variation in bacteria. Clin Microbiol Rev. 2004;17:581-611.

37. Coutinho PM, Deleury E, Davies GJ, Henrissat B. An evolving hierarchical family classification for glycosyltransferases. J Mol Biol. 2003;328:307-17.

38. Yin $Y$, Mao $X$, Yang JC, Chen $X$, Mao F, Xu Y. dbCAN: a web resource for automated carbohydrate-active enzyme annotation. Nucleic Acids Res. 2012;40: W445-51.

39. Knirel YA, Shashkov AS, Tsvetskov YE, Jansson P-E, Zähringer U. 5,7-diamino3,5,7,9-tetradeoxynon-2-ulosonic acids in bacterial glycopolymers: chemistry and biochemistry. Adv Carbohydr Chem Biochem. 2003;58:317-417.

40. Linton D, Karlyshev AV, Hitchen PG, Morris HR, Dell A, Gregson NA, et al. Multiple N-acetyl neuraminic acid synthetase (neuB) genes in Campylobacter jejuni: identification and characterization of the gene involved in sialylation of lipo-oligosaccharide. Mol Microbiol. 2000;35:1120-34.

41. Steenbergen SM, Vimr ER. Chromatographic analysis of the Escherichia coli polysialic acid capsule. Methods Mol Biol. 2013;966:109-20.

42. Daines DA, Silver RP. Evidence for multimerization of Neu proteins involved in polysialic acid synthesis in Escherichia coli K1 using improved LexA-based vectors. J Bacteriol. 2000;182:5267-70.

43. Daines DA, Wright LF, Chaffin DO, Rubens CE, Silver RP. NeuD plays a role in the synthesis of sialic acid in Escherichia coli K1. FEMS Microbiol Lett. 2000;189:281-4.

44. Iguchi A, lyoda S, Kikuchi T, Ogura Y, Katsura K, Ohnishi M, et al. A complete view of the genetic diversity of the Escherichia coli O-antigen biosynthesis gene cluster. DNA Res. 2015;22:101-7.

45. Ricaldi JN, Matthias MA, Vinetz JM, Lewis AL. Expression of sialic acids and other nonulosonic acids in Leptospira. BMC Microbiol. 2012;12:161.

46. Schoenhofen IC, McNally DJ, Brisson J-R, Logan SM. Elucidation of the CMPpseudaminic acid pathway in Helicobacter pylori: synthesis from UDP-Nacetylglucosamine by a single enzymatic reaction. Glycobiol. 2006;16:8-14.

47. Li Z, Hwang S, Ericson J, Bowler K, Bar-Peled M. Pen and Pal are nucleotidesugar dehydratases that convert UDP-GICNAc to UDP-6-deoxy-D-GICNAc-5,6-ene and then UDP-4-keto-6-deoxy-L-AltNAc for CMP-pseudaminic acid synthesis in Bacillus thuringiensis. J Biol Chem. 2015:290:691-704.

48. Schirm M, Schoenhofen IC, Logan SM, Waldron KC, Thibault P. Identification of unusual bacterial glycosylation by tandem-mass spectrometry analyses of intact proteins. Analyt Chem. 2005;77:7774-82. 
49. Novotny R, Schäffer C, Strauss J, Messner P. S-layer glycan-specific loci on the chromosome of Geobacillus stearothermophilus NRS 2004/3a and dTDP-Lrhamnose biosynthesis potential of $\mathrm{G}$. stearothermophilus strains. Microbiol. 2004;150:953-65.

50. Pföstl A, Zayni S, Hofinger A, Kosma P, Schäffer C, Messner P. Biosynthesis of dTDP-3-acetamido-3,6-dideoxy-alpha-D-glucose. Biochem J. 2008:410:187-94.

51. Richards MR, Lowary TL. Chemistry and biology of galactofuranose-containing polysaccharides. ChemBioChem. 2009;10:1920-38.

52. Messner P, Steiner K, Zarschler K, Schäffer C. S-layer nanoglycobiology of bacteria. Carbohydr Res. 2008;343:1934-51.

53. Bhavsar AP, Beveridge TJ, Brown ED. Precise deletion of tagD and controlled depletion of its product, glycerol 3-phosphate cytidylyltransferase, leads to irregular morphology and lysis of Bacillus subtilis grown at physiological temperature. J Bacteriol. 2001;183:6688-93.

54. Morein S, Trouard TP, Hauksson JB, Rilfors L, Arvidson G, Lindblom G. Twodimensional H-NMR of the transmembrane peptides from Escherichia coli phosphatidylglycerophosphate synthase in micelles. Eur J Biochem. 1996;241:489-97.

55. Jarrell HC, Jones GM, Kandiba L, Nair DB, Eichler J. S-layer glycoproteins and flagellins: reporters of archaeal posttranslational modification. Archaea. 2010;2010:612948.

56. Chiku K, Yamamoto M, Ohnishi-Kameyama M, Ishii T, Yoshida M, Taguchi F, et al. Comparative analysis of flagellin glycans among pathovars of phytopathogenic Pseudomonas syringae. Carbohyd Res. 2013;375:100-4.

57. Gonzaga A, Martin-Cuadrado A-B, López-Pérez M, Megumi Mizuno C, García-Heredia I, Kimes NE, et al. Polyclonality of concurrent natural populations of Alteromonas macleodii. Genome Biol Evol. 2012;4:1360-74.

58. Fortina M, Mora D, Schumann P, Parini C, Manachini P, Stackebrandt E. Reclassification of Saccharococcus caldoxylosilyticus as Geobacillus caldoxylosilyticus (Ahmad et al. 2000) comb. nov. Int J Syst Evol Microbiol. 2001;51:2063-71.

59. Melgaard M, Svendsen I. Different effects of $\mathrm{N}$-glycosylation on the thermostability of highly homologous bacterial (1,3-1,4)-beta glucanases secreted from yeast. Microbiol. 1994;140:159-66.

60. Borodovsky M, Mclninch J. GeneMark: parallel gene recognition for both DNA strands. Comput Chem. 1993:17:123-33.

61. Hall TA. BioEdit: a user-friendly biological sequence alignment editor and analysis program for Windows 95/98/NT. Nucleic Acids Res Symp Ser. 1999:41:95-8.

62. Marchler-Bauer A, Bryant SH. CD-search: protein domain annotations on the fly. Nucleic Acids Res. 2004;32:327-31.

63. Katoh K, Standley DM. MAFFT Multiple Sequence Alignment Software version 7: improvements in performance and usability. Mol Biol Evol. 2013;30:772-80.

64. Kumar S, Nei M, Dudley J, Tamura K. MEGA: a biologist-centric software for evolutionary analysis of DNA and protein sequences. Briefs Bioinf. 2008:9:299-306.

65. Felsenstein J. PHYLIP - Phylogeny inference package (version 3.2). Cladistics. 1989;5:164-6.

66. LabArchive repository. https://mynotebook.labarchives.com/share/ Geobacillus_FGI_Manuscript/MC4wfDE4OTc2NS8wL1RyZWVOb2RILz M2OTEzMTlyMDh8MC4w.

67. Treebase Repository. http://purl.org/phylo/treebase/phylows/study/TB2: S20124.

\section{Submit your next manuscript to BioMed Central and we will help you at every step:}

- We accept pre-submission inquiries

- Our selector tool helps you to find the most relevant journal

- We provide round the clock customer support

- Convenient online submission

- Thorough peer review

- Inclusion in PubMed and all major indexing services

- Maximum visibility for your research

Submit your manuscript at www.biomedcentral.com/submit
Biomed Central 